\title{
Effect of Zirconium on Microstructure and Mechanical Properties of Cast Fine-Grain CM 247 LC Superalloy
}

\author{
Hsin-Erh Huang*1 and Chun-Hao Koo*2 \\ Department of Materials Science and Engineering, National Taiwan University, Taipei, Taiwan 106, R. O. China
}

This study investigates the effect of $\mathrm{Zr}$ minor additions, with $\mathrm{Zr}$ content from 0.015 to 0.15 mass $\%$, on microstructure and mechanical properties of fine-grain $(65 \mu \mathrm{m}) \mathrm{CM} 247 \mathrm{LC}$ superalloy. Tensile test results indicate that minor addition of $\mathrm{Zr}$ to fine-grain CM $247 \mathrm{LC}$ can dramatically improve the yield strength at $300 \mathrm{~K}$ as well as both the yield strength and the elongation at $1033 \mathrm{~K}$. Under creep conditions of $1033 \mathrm{~K} / 725 \mathrm{MPa}$ or $1200 \mathrm{~K} / 345 \mathrm{MPa}$, the $\mathrm{Zr}$ additions drastically increased the rupture life, creep rate and elongation. The AES observation reveal that $\mathrm{Zr}$ may enrich at grain-boundary and boride/matrix interface and dissolve in matrix, carbide or $\gamma^{\prime}$ phase. Thus, Zr may change the primary MC carbide characteristics and inhibit the script-like MC carbide formation. Moreover, $\mathrm{Zr}$ is apparently to increase the effects of the cohesive energy of both the precipitated phase/matrix interface and the grain boundaries, also it is beneficial to stress accommodation and retards the crack initiation and propagation.

(Received October 24, 2003; Accepted December 25, 2003)

Keywords: Cannon-Muskegon 247 Low-Carbon Superalloy, Microcast-X casting process, zirconium, tensile strength, creep resistance

\section{Introduction}

The turbine disk and blades of many small gas turbines, such as small aircraft engines, turbo-fan missile engines and vehicular engines, are usually cast into a single piece, generally known as "integral wheels". The operating temperature of the turbine disk typically does not exceed $1033 \mathrm{~K}$. The operating stresses, associated with the centrifugal loads of these rotating components are high at the rim and toward the center, and usually exceed $550 \mathrm{MPa}$. However, turbine blades are subject to relatively low stresses, generally below $345 \mathrm{MPa}$, but high operating temperatures. Materials used to construct integral wheel must possess the combined properties of blade and disk. These materials, therefore, must have a very high tensile strength at operating temperature of the hub to protect the parts from bursting and high creep strength under blade operating condition. ${ }^{1)}$

Controlling the grain size is an important means of developing and maintaining both physical and mechanical properties. Microcast-X casting, developed by the Howmet Turbine Components Corporation, has been successfully demonstrated to generate fine-grain components that range from turbine disks to blades and vanes. Many fine-grain turbine wheels have been extensively cast with IN 713 LC, IN 718 and Mar-M247 nickel-based superalloys. ${ }^{1-3)}$ The rigid requirements of increased operating temperatures of integral turbine wheels, increased rotational speeds and extended lifetimes of components have forced designers of turbine engines to tighten their criteria for selecting alloys.

CM 247 LC is a cast nickel-based superalloy with a low carbon content. The alloy is a modified superalloy based on the chemical composition of Mar-M247, specifically designed for making directionally solidified (DS) turbine blades. ${ }^{4-6)}$ The previous study ${ }^{7}$ indicates that when the casting parameters are well controlled, the CM 247 LC superalloy has an excellent castability to form an equiaxed

\footnotetext{
${ }^{* 1}$ Graduate Student, National Taiwan University

${ }^{* 2}$ Corresponding author, E-mail: chkoo@ccms.ntu.edu.tw
}

grain structure, with high strength and superior creep resistance. However, the elements $(\mathrm{B}, \mathrm{Zr})$ for grain boundary strengthening may be insufficient for generating a conventionally polycrystalline superalloy under fine-grain casting conditions. Consequently, studying the relationship between grain boundary chemistry and the mechanical characteristics of cast fine-grain superalloy is important.

The Microcast-X casting process, producing test specimens of CM 247 LC superalloy with controlled fine-grain structures, was performed herein. The aim of this study is to elucidate the microstructural characteristics and investigate the mechanical performance of the fine-grain CM 247 LC superalloy with various $\mathrm{Zr}$ additions. Furthermore, some mechanisms associated with microstructure and mechanical properties are discussed.

\section{Experimental Procedure}

The alloys used herein were originally melted by vacuum induction melting (VIM) at the Cannon-Muskegon Corporation in USA. The alloys were remelted in an alumina crucible in a VIM furnace and poured at $1643 \mathrm{~K}$ into a ceramic shell mold with a $\mathrm{CoO}$ facecoat at Chung Shan Institute of Science and Technology in Taiwan. The temperature of the ceramic shell mold was maintained at $1373 \mathrm{~K}$. Four heats of fine-grain CM 247 LC superalloys with $\mathrm{Zr}$ contents from 0.015 mass $\%$ to 0.15 mass $\%$ were prepared during fine-grained casting. After casting, the major elemental constituents were detected by X-ray fluorescence (XRF). Table 1 presents the nominal compositions of the parent alloys used herein. After casting all test bars underwent hot isostatic pressing (HIP) at $1458 \mathrm{~K} / 173 \mathrm{MPa} / 4 \mathrm{~h}$ in an atmosphere of argon. The specimens produced were then heat-treated in a vacuum furnace. The heat treatment processes consisted of solution treatments at $1494 \mathrm{~K} / 2 \mathrm{~h}$, followed by argon gas fan quenching (Ar-GFQ), subsequently aging treatments at $1144 \mathrm{~K} / 20 \mathrm{~h}$, and finally furnace cooling. The grain size was measured using the linear intercept method. The microstructure and fracture surface 
Table 1 Nominal composition (mass\%) of fine-grain CM 247 LC with various $\mathrm{Zr}$ contents.

\begin{tabular}{ccllll}
\hline Composition & CM 247 LC & CZ1 & CZ2 & CZ3 & CZ4 \\
\hline Cr & $8.0 \sim 8.5$ & 8.1 & 8.2 & 8.1 & 8.1 \\
Co & $9.0 \sim 9.5$ & 9.3 & 9.29 & 9.4 & 9.32 \\
W & $9.3 \sim 9.7$ & 9.4 & 9.4 & 9.4 & 9.4 \\
Mo & $0.4 \sim 0.6$ & 0.58 & 0.58 & 0.58 & 0.58 \\
$\mathrm{Ta}$ & $3.1 \sim 3.3$ & 3.26 & 3.3 & 3.3 & 3.3 \\
$\mathrm{Al}$ & $5.4 \sim 5.7$ & 5.5 & 5.51 & 5.6 & 5.6 \\
$\mathrm{Ti}$ & $0.6 \sim 0.9$ & 0.68 & 0.72 & 0.72 & 0.7 \\
$\mathrm{Hf}$ & $1.0 \sim 1.6$ & 1.35 & 1.42 & 1.34 & 1.35 \\
$\mathrm{C}$ & $0.07 \sim 0.08$ & 0.08 & 0.08 & 0.08 & 0.08 \\
$\mathrm{~B}$ & $0.01 \sim 0.02$ & 0.015 & 0.015 & 0.015 & 0.015 \\
$\mathrm{Zr}$ & $0.007 \sim 0.02$ & 0.015 & 0.04 & 0.08 & 0.15 \\
$\mathrm{Ni}$ & $\mathrm{BAL}$ & $\mathrm{BAL}$ & $\mathrm{BAL}$ & $\mathrm{BAL}$ & $\mathrm{BAL}$ \\
\hline
\end{tabular}

were observed using optical microscopy $(\mathrm{OM})$ and scanning electron microscopy (SEM). The segregation of $\mathrm{Zr}$ was analyzed by Auger electron spectrometry (AES). Specimens were impacted in the vacuum chamber of the Auger spectroscope at a liquid nitrogen temperature to obtain a fresh fracture surface, and thereby minimize contamination of the specimen and absorption of surface gas. Tensile tests were performed at $300 \mathrm{~K}$ and $1033 \mathrm{~K}$, using an Instron 1125 mechanical testing machine. Creep tests were conducted at $1033 \mathrm{~K} / 725 \mathrm{MPa}$ or $1200 \mathrm{~K} / 345 \mathrm{MPa}$ using SATEC M3 creep testers. The gauge size of the test bars was $6.3 \mathrm{~mm}$ in diameter and $25.4 \mathrm{~mm}$ in length.

\section{Results}

\subsection{Microstructure and carbide morphology}

Figure 1 depicts the typical as-cast microstructure of the fine-grain CM 247 LC superalloy. The structure comprises a $\gamma^{\prime}$ intermetallic phase dispersed in a $\gamma$ matrix. The rosette structure of the primary $\gamma-\gamma^{\prime}$ eutectic phase was observed mainly at the grain boundaries, with only a small portion within the grains. Additionally, the as-cast MC carbide has a predominantly irregular shape in the grains and at the grain boundaries.

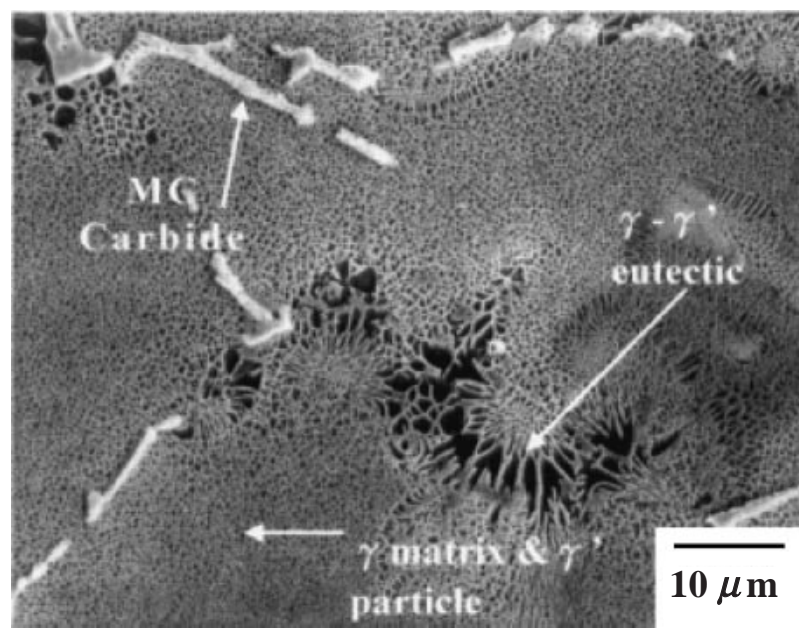

Fig. 1 The microstructure of cast fine-grain CM 247 LC superalloy.
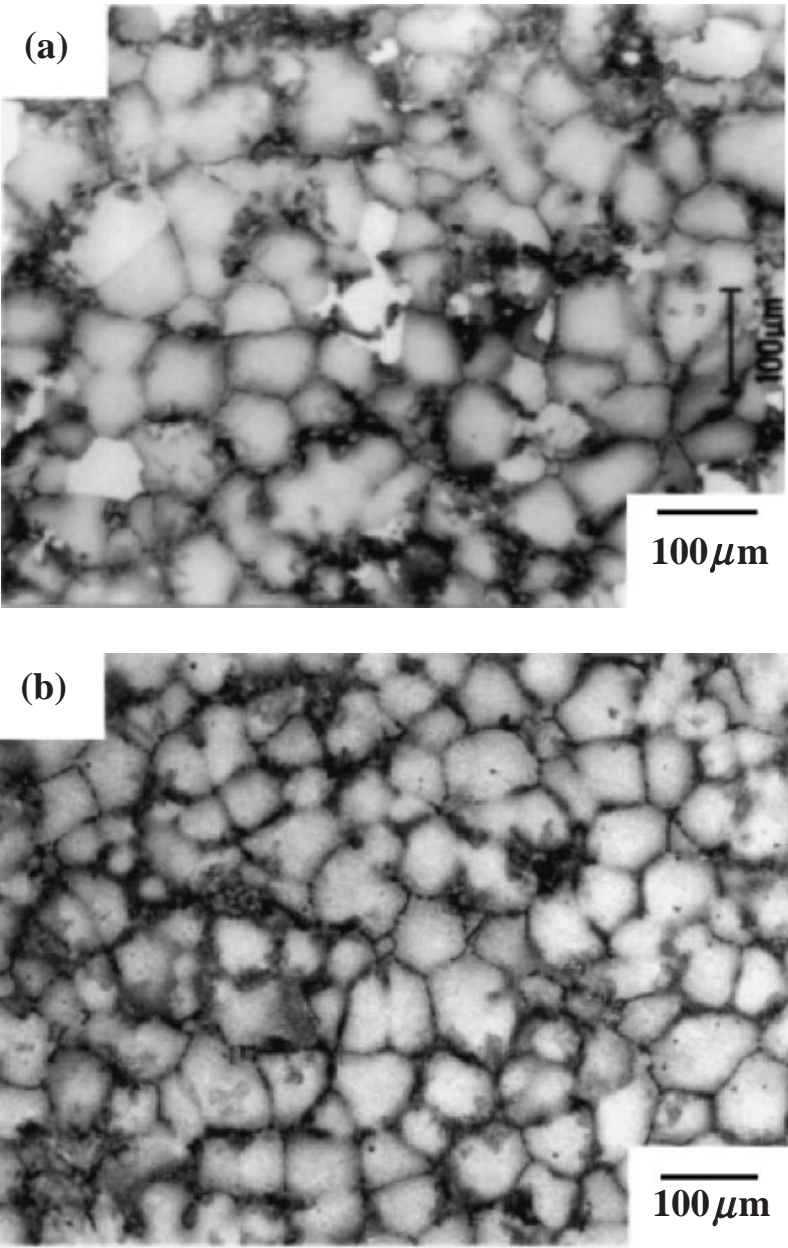

Fig. 2 The grain size of cast fine-grain CM 247 LC $(65 \mu \mathrm{m})$ with (a) 0.015 mass $\% \mathrm{Zr}$, and (b) 0.15 mass $\% \mathrm{Zr}$.

Minor additions of $\mathrm{Zr}$ were observed not to affect the grain size of the fine-grain CM 247 LC superalloy. The average grain size of approximately $65 \mu \mathrm{m}$ determined in the study as shown in Fig. 2 was obtained by maintaining the pouring temperature about $10 \mathrm{~K}$ above the liquidus. The fine-grain alloy produced by the Microcast-X casting process results in a substantially cellular and nondendritic microstructure. However, $\mathrm{Zr}$ additions greatly altered morphology of the carbides. Coarse and script-like carbides are present in the fine-grain CM 247 LC superalloy, and their sizes are in excess of $30 \mu \mathrm{m}$ (Fig. 3(a)). As revealed in Figs. 3(b)-(d), minor $\mathrm{Zr}$ addition changed the carbide morphology from coarse and script-like to fine and spherical. The $\gamma^{\prime}$ size of fine-grain CM 247 LC superalloy with various $\mathrm{Zr}$ contents following heat-treatment at HIPing $+1494 \mathrm{~K} / 2 \mathrm{~h}$ GFQ + $1144 \mathrm{~K} / 20 \mathrm{~h} \mathrm{~F}$.C. is about $0.15 \mu \mathrm{m}$, and the morphology of the $\gamma^{\prime}$ is fine and globular, as shown in Fig. 4.

\subsection{Tensile properties at $300 \mathrm{~K}$ and $1033 \mathrm{~K}$}

Table 2 presents the tensile properties at $300 \mathrm{~K}$ and $1033 \mathrm{~K}$ of fine-grain CM 247 LC superalloy with various $\mathrm{Zr}$ contents. The yield strength at $300 \mathrm{k}$ increases from $1020 \mathrm{MPa}$ for test bars with 0.015 mass $\% \mathrm{Zr}$ to $1095 \mathrm{MPa}$ for test bars with 0.15 mass $\% \mathrm{Zr}$. Furthermore, the ultimate tensile strength and elongation at room temperature change only slightly with the $\mathrm{Zr}$ content. At $1033 \mathrm{~K}$, the fine grain structure retains its 

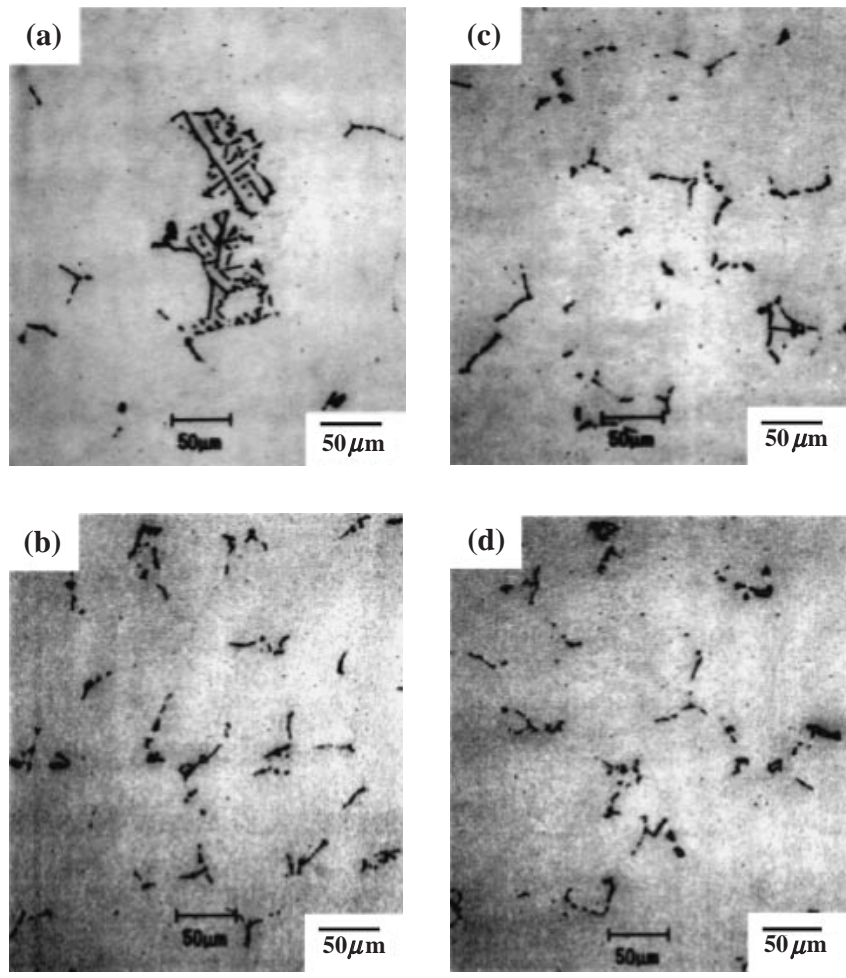

Fig. 3 The morphology of carbide in fine-grain CM 247 LC superalloy with the content of (a) 0.015 mass $\% \mathrm{Zr}$ (b) 0.04 mass $\% \mathrm{Zr}$ (c) 0.08 mass $\%$ $\mathrm{Zr}$ (d) 0.15 mass $\% \mathrm{Zr}$.

strength and elongation. As shown in Table 2, the yield strength increases from $1020 \mathrm{MPa}$, for test bars with 0.015 mass $\% \mathrm{Zr}$, to $1053 \mathrm{MPa}$ for test bars with 0.15 mass $\%$ $\mathrm{Zr}$; the elongation increases from 8.3 to $9.7 \%$ as the $\mathrm{Zr}$ content is increased from 0.015 to 0.15 mass $\%$. Similar results are also obtained for ultimate strength, which increases from $1190 \mathrm{MPa}$ up to $1220 \mathrm{MPa}$ as the $\mathrm{Zr}$ content is increased as stated. Consequently, the tensile test results indicate that the minor addition of $\mathrm{Zr}$ increases yield strength at both room temperature and $1033 \mathrm{~K}$.

\subsection{Creep tests at $1033 \mathrm{~K} / 725 \mathrm{MPa}$ and $1200 \mathrm{~K} / 345 \mathrm{MPa}$}

Table 3 shows that the creep life and ductility of polycrystalline CM $247 \mathrm{LC}$ at $1033 \mathrm{~K} / 725 \mathrm{MPa}$ at any specified $\mathrm{Zr}$ content; increasing the $\mathrm{Zr}$ content can remarkably enhance the creep life and ductility at $1033 \mathrm{~K} / 725 \mathrm{MPa}$. When the $\mathrm{Zr}$ content is 0.15 mass $\%$, the rupture elongation and creep life are $4.8-5.0 \%$ and $154-162 \mathrm{~h}$, respectively. In other words, the rupture life of fine grain CM 247 LC with 0.15 mass $\% \mathrm{Zr}$ is approximately 2.5 times greater than that of the 0.015 mass $\% \mathrm{Zr}$. In particular, the $1 \%$ creep life increases from $37 \mathrm{~h}$, for test bars with 0.015 mass $\% \mathrm{Zr}$, to $67 \mathrm{~h}$ for test bars with 0.15 mass $\% \mathrm{Zr}$.

According to Table 4, under creep conditions of high temperature and moderate stress ( $1200 \mathrm{~K} / 345 \mathrm{MPa})$, increasing the $\mathrm{Zr}$ content can substantially increase the creep life and ductility. When the $\mathrm{Zr}$ content exceeds 0.08 mass $\%$, the rupture elongation and life can reach $10.3-11.0 \%$ and 35$38 \mathrm{~h}$, respectively. Restated, the rupture life of fine grain CM $247 \mathrm{LC}$ with 0.08 mass \% $\mathrm{Zr}$ is approximately double that with 0.015 mass $\% \mathrm{Zr}$. In particular, the $1 \%$ creep life increases from $9 \mathrm{~h}$ for test bars with 0.015 mass $\% \mathrm{Zr}$ to $14 \mathrm{~h}$ for test bars of 0.08 mass\% Zr. Apparently, optimal minor $\mathrm{Zr}$ additions enhance both the rupture elongation and the life of the fine-grain CM 247 LC superalloy.

\subsection{AES analysis}

AES was employed for interfacial segregation analysis to investigate the effect of $\mathrm{Zr}$ on microstructural characteristics. Standard AES samples with 0.015 mass $\%$ and with 0.15 mass $\% \mathrm{Zr}$ were prepared and treated with liquid nitrogen for $4 \mathrm{~h}$ before being impact-tested. Figure 5(a) displays a secondary image of the fractured surface of a 0.015 mass $\% \mathrm{Zr}$ specimen, wherein five typically distinct areas are marked as area 1 to area 5 . In this analysis, no or a limited amount of $\mathrm{Zr}$ is detected in areas 1 to 5. Figures 5(b)-(c) are the corresponding Auger spectra, revealing areas that correspond to the matrix (area 3) and the MC carbide (area 5), respectively. Apparently, a limited amount of $\mathrm{Zr}$ is detected in the matrix and in the interior of the carbide. Moreover, Fig. 6 presents a secondary image of the fractured surface of a 0.15 mass\% $\mathrm{Zr}$ specimen, wherein three typically distinct areas are selected and marked, including areas 1 to 3. Figures 7(a)-(c) are the corresponding Auger spectra, revealing boride (area 1), carbide (area 2) and matrix (area 3). Clearly, the $\mathrm{Zr}$ peaks in the spectra of the areas are detected, indicate $\mathrm{Zr}$ enriches at the boride/matrix interface, at the carbide/ matrix interface, and at the grain boundaries. Furthermore, the depth of $\mathrm{Zr}$ segregation is determined in three distinct areas (areas 1 to 3) selected for ion sputtering. The speed of ion sputtering is $0.8 \mathrm{~nm} / \mathrm{min}$. Figures $7(\mathrm{~d})-(\mathrm{f})$ show the test spectra of areas 1 to 3 following ion sputtering. Firstly, no or limited $\mathrm{Zr}$ is detected after 10 mins of sputtering in area $1 . \mathrm{Zr}$ is thus shown to segregate at the boride/matrix interface. Secondly, a large quantity of $\mathrm{Zr}$ is detected after 25 mins of sputtering in area 2 . $\mathrm{Zr}$ is thus proven to be in solid solution in MC carbide when $\mathrm{Zr}$ is added. Finally, no or limited $\mathrm{Zr}$ is detected after 20 mins of sputtering in area 3, implying that $\mathrm{Zr}$ segregates at the grain boundaries. Those results indicate that $\mathrm{Zr}$ segregates at the boride/matrix interface or at the grain boundaries, and in solid solution in MC carbides.

\section{Discussion}

\subsection{Mechanisms of $\mathrm{Zr}$ segregation strengthening}

One of the most remarkable alloying effects in a superalloy is the enhancement of creep properties when minute amounts of boron and zirconium are added. ${ }^{8)}$ Boron and zirconium clearly retard the grain boundary cracking. The case of early U-500 alloy is a good example. ${ }^{8)}$ In U-500 without boron and zirconium, microcracks developed at the end of first-stage creep at $23 \mathrm{~h}$; but with boron and zirconium, microcracks did not develop until third-stage creep at $214 \mathrm{~h}$. A general mechanism of the above effects is that odd-size atoms (21$29 \%$ oversize or undersize) segregate at grain boundaries, filling vacancies and reducing grain boundary diffusion. ${ }^{9)}$

A later work ${ }^{10)}$ has revealed a new mechanism, by which zirconium has been found to form $\mathrm{Zr}_{4} \mathrm{C}_{2} \mathrm{~S}_{2}$, significantly reducing the amount of elemental sulfur at the grain boundaries and retarding the generation of grain boundary cracking. In this work, however, the contents of S, P and 

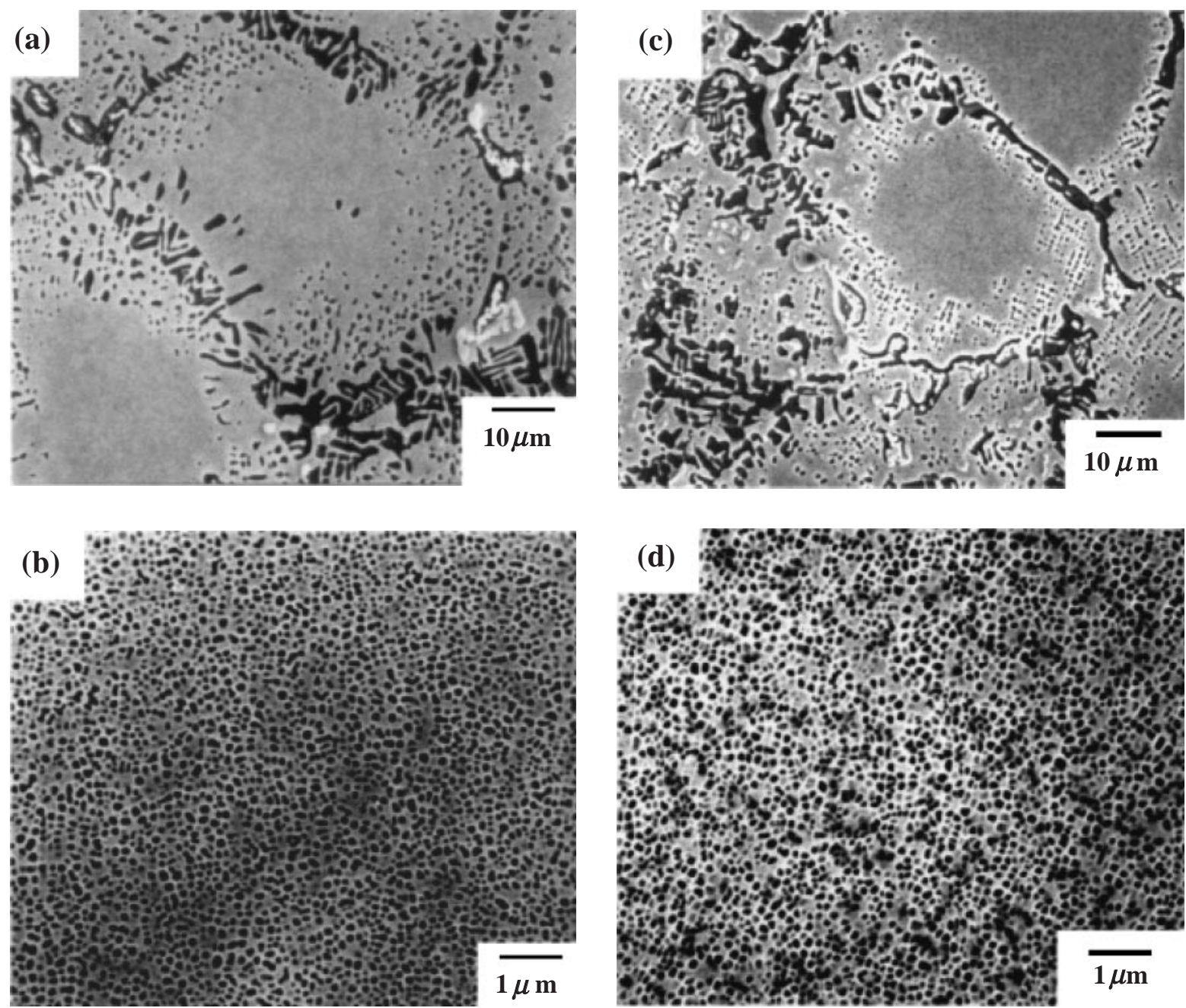

Fig. 4 SEM micrographs showing the distribution and size of $\gamma^{\prime}$ phase of fine-grain CM $247 \mathrm{LC}$ superalloy with $0.015 \mathrm{mass} \% \mathrm{Zr}$ after heat treatment (HIPing $+1494 \mathrm{~K} / 2 \mathrm{~h}+1144 \mathrm{~K} / 20 \mathrm{~h}$ ) and the observation at (a) grain boundary, and (b) the center of grain as well as finegrain CM $247 \mathrm{LC}$ superalloy with 0.15 mass\% $\mathrm{Zr}$ after heat treatment (HIPing $+1494 \mathrm{~K} / 2 \mathrm{~h}+1144 \mathrm{~K} / 20 \mathrm{~h}$ ) and the observation at (c) grain boundary, and (d) the center of grain.

Table 2 Tensile test results of fine-grain CM $247 \mathrm{LC}$ with various Zr contents. (Material Condition: HIPing $+1494 \mathrm{~K} / 2 \mathrm{~h}+1144 \mathrm{~K} / 20 \mathrm{~h}$ )

\begin{tabular}{ccccc}
\hline Condition & Test Temp. (K) & U.T.S. (MPa) & Y.S. (MPa) & Elongation (\%) \\
\hline CZ1(0.015 mass\% Zr) & 300 & 1242 & 1020 & 8.2 \\
CZ2(0.040 mass\% Zr) & 300 & 1238 & 1026 & 7.7 \\
CZ3(0.080 mass\% Zr) & 300 & 1273 & 1062 & 8.0 \\
CZ4(0.150 mass\% Zr) & 300 & 1230 & 1095 & 7.6 \\
CZ1(0.015 mass\% Zr) & 1033 & 1190 & 1020 & 8.3 \\
CZ2(0.040 mass\% Zr) & 1033 & 1215 & 1040 & 8.7 \\
CZ3(0.080 mass\% Zr) & 1033 & 1215 & 1049 & 9.8 \\
CZ4(0.150 mass\% Zr) & 1033 & 1220 & 1053 & 9.7 \\
\hline
\end{tabular}

Table 3 The creep test results of fine-grain CM $247 \mathrm{LC}$ with various $\mathrm{Zr}$ contents at 1033 K/725 MPa. (Material Condition: HIPing + $1494 \mathrm{~K} / 2 \mathrm{~h}+1144 \mathrm{~K} / 20 \mathrm{~h})$

\begin{tabular}{cccc}
\hline Condition & Creep life $(\mathrm{h})$ & Elongation $(\%)$ & $1 \%$ Creep life $(\mathrm{h})$ \\
\hline CZ1(0.015 mass\% Zr) & $40 \sim 61$ & $3.0 \sim 3.3$ & 37 \\
CZ2(0.040 mass\% Zr) & $110 \sim 113$ & $3.3 \sim 3.8$ & 51 \\
CZ3(0.080 mass\% Zr) & $124 \sim 140$ & $3.8 \sim 4.7$ & 53 \\
CZ4(0.150 mass\% Zr) & $154 \sim 162$ & $4.8 \sim 5.0$ & 67 \\
\hline
\end{tabular}


Table 4 The creep test results of fine-grain CM 247 LC with various $\mathrm{Zr}$ contents at $1200 \mathrm{~K} / 345 \mathrm{MPa}$. (Material Condition: HIPing + $1494 \mathrm{~K} / 2 \mathrm{~h}+1144 \mathrm{~K} / 20 \mathrm{~h})$

\begin{tabular}{ccccc}
\hline Condition & Creep life $(\mathrm{h})$ & Elongation $(\%)$ & $1 \%$ Creep life $(\mathrm{h})$ \\
\hline CZ1 $(0.015$ mass\% Zr) & $15-23$ & $7.8-9.4$ & $9.8-10.5$ & 12 \\
CZ2(0.040 mass\% Zr) & $28-32$ & $10.3-11.0$ & 14 \\
CZ3(0.080 mass\% Zr) & $35-38$ & $10.2-10.5$ & 15 \\
CZ4 $(0.150$ mass\% Zr) & $36-38$ & & \\
\hline
\end{tabular}
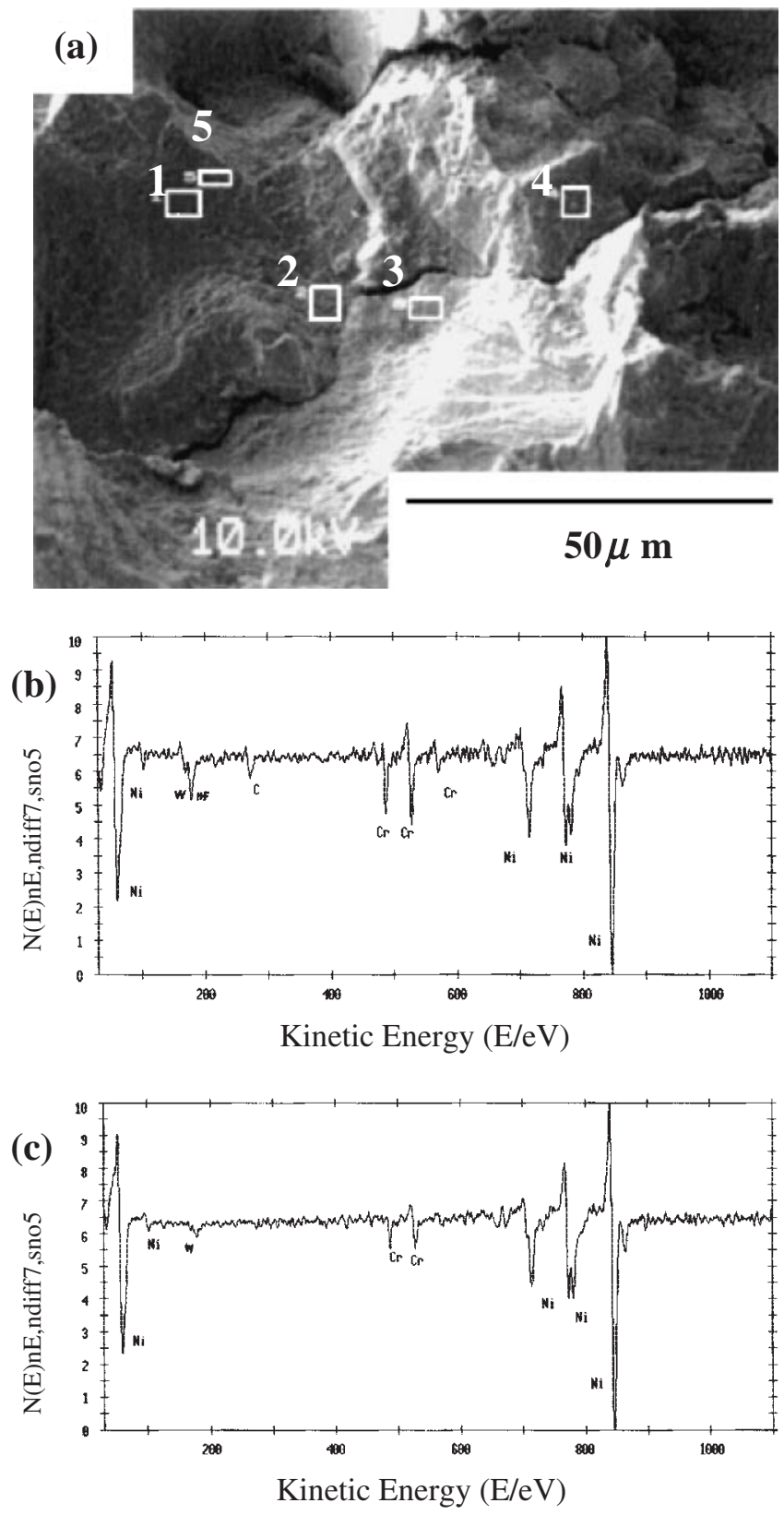

Fig. 5 Fine-grained CM 247 LC superally with 0.015 mass $\% \mathrm{Zr}$ (a) the area of the AES analysis, (b) the spectrum at area 3, and (c) the spectrum at area 5 .

other trace elements were far below $5 \mathrm{ppm}$. Therefore, the $\mathrm{Zr}_{4} \mathrm{C}_{2} \mathrm{~S}_{2}$ phase was observed neither at the matrix/carbides interfaces nor in the GBs, according to the analysis of AES in fine-grain CM 247 LC with various $\mathrm{Zr}$ contents. Thus, an improvement of the high-temperature mechanical properties of fine-grain CM 247 LC may not be directly related to the

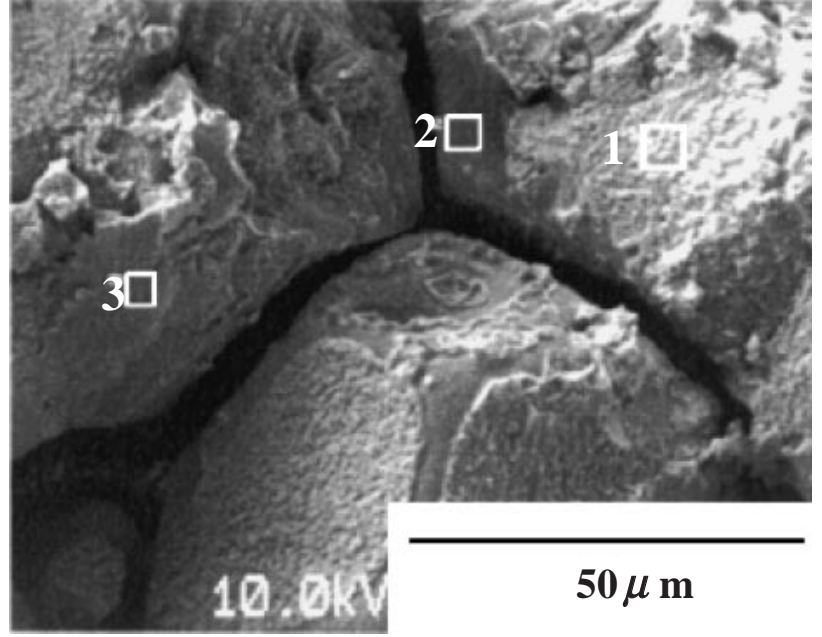

Fig. 6 The area of the AES analysis for fine-grain CM 247 LC superalloy with 0.15 mass $\% \mathrm{Zr}$.

getting mechanism.

According to the present AES results, $\mathrm{Zr}$ enriches at austenitic boundaries, carbide or the boride/matrix interfaces. Computer simulations ${ }^{11)}$ have suggested that microcavities at grain boundaries are on the atomic scale and extremely dense. Hence, the grain boundary can be considered effectively as a very thin layer of porous material, which has a very low effective elastic modulus and, therefore, reduced shear stress transmission. In order to minimize the energy, $\mathrm{Zr}$ thus tends to fill lattice discontinuities at interface boundaries or grain boundaries, increasing the structural regularity and the strength of bonds between the angulated lattices.

\subsection{Mechanisms of $\mathrm{Zr}$ solid-solution strengthening}

Nickel-based superalloy is strengthened primarily by the $\gamma^{\prime}$ phase in the matrix. The $\mathrm{Ni}-\mathrm{Al}$ phase diagram indicates that the $\mathrm{Ni}_{3} \mathrm{Al}$ phase has a broad range of chemical compositions. A region with an $\mathrm{Al}$ content from 23 to 27.5 at $\%$ is single-phase, and the Al content increases as the temperature increases. ${ }^{12)}$ The broad range of chemical compositions implies that the stable secondary phase can be formed easily. The atoms of the $\mathrm{Ni}_{3} \mathrm{Al}$ are replaced by three types of the elements, that depending on the positions of the replacements. ${ }^{13)}$ Replacement at the position of the $\mathrm{Al}$ atom is by such atoms as $\mathrm{Si}, \mathrm{Ge}, \mathrm{Ti}, \mathrm{V}, \mathrm{Hf}, \mathrm{Zr}, \mathrm{Mo}, \mathrm{W}$, or $\mathrm{Nb}$, whereas replacement at the position of the $\mathrm{Ni}$ atom is by such atoms as $\mathrm{Cu}, \mathrm{Co}$, or $\mathrm{Pt}$, and replacement at positions of both $\mathrm{Ni}$ and $\mathrm{Al}$ atoms are by such atoms as $\mathrm{Fe}, \mathrm{Mn}$, or $\mathrm{Cr}$. $\mathrm{Hf}$ and $\mathrm{Zr}$ are the most effectively strengthening elements in $\mathrm{Ni}_{3} \mathrm{Al}$, because of the size of the atoms, difference between the 

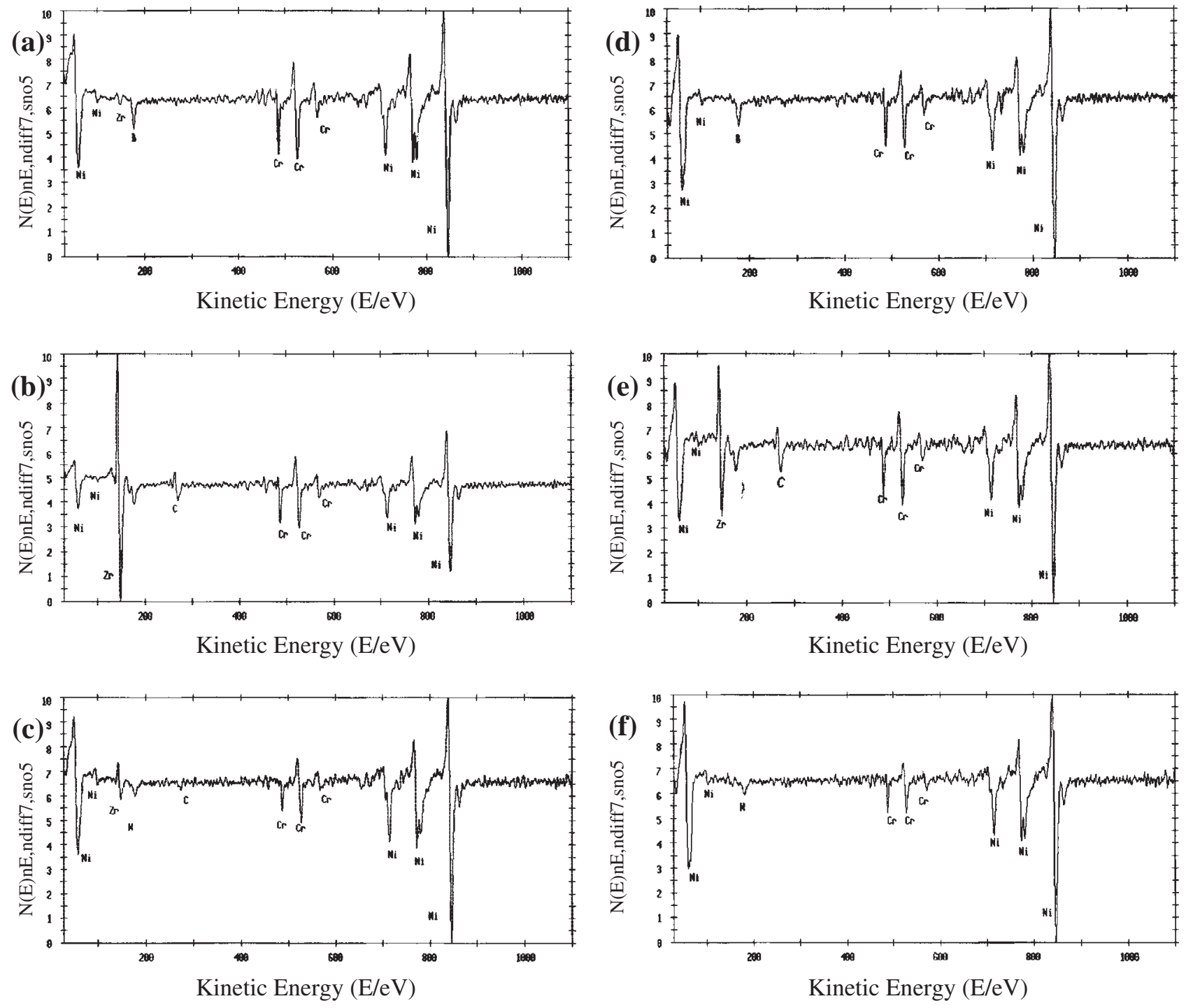

Fig. 7 The spectrum of the AES analysis before ion sputtering at (a) area 1, (b) area 5, (c) area 3 for fine-grain CM 247 LC superally with 0.15 mass \% $\mathrm{Zr}$ and after ion sputtering at (d) area 1, (e) area 2, (f) area 3.

valence of these atoms, the APB energy, and the energy associated with cross-slip on the (100) face.

$\mathrm{Liu}^{14)}$ and $\mathrm{Hsu}^{15)}$ found two reasons for strengthening by $\mathrm{Hf}$ and $\mathrm{Zr}$. Firstly, both $\mathrm{Hf}$ and $\mathrm{Zr}$ increase the CRSS (critical resolved shear stress) on the (100) face and only weakly affect the (111) face. Thus, it increases the temperature of transfer from the $\{111\}\langle 110\rangle$ slip system to the $\{100\}\langle 110\rangle$ slip system. However, some elements, such as Mo, Ta, Nb, Ti and $\mathrm{W}$, decrease the CRSS on the $\{100\}\langle 110\rangle$ slip system. Secondly, both Hf and $\mathrm{Zr}$ reduce the APB energy, increasing the rate of the cross-slip from $\{111\}$ to $\{100\}$ associated with super-dislocation. This study found little evidence of $\mathrm{Zr}$ segregation in 0.015 mass \% Zr specimens. Clearly, Zr prefers to dissolve in solid-solution in matrix $\left(\gamma\right.$ or $\left.\gamma^{\prime}\right)$ of 0.015 mass $\% \mathrm{Zr}$ specimens, because the $\mathrm{Zr}$ content is relatively low.

\subsection{Effect of $\mathrm{Zr}$ on carbide morphology}

In the late 1970s, alloy designers added Hf to nickel-based superalloys to produce the $\gamma-\gamma^{\prime}$ eutectic phase and enhance the GB's toughness. ${ }^{16-18)}$ However, nickel-based cast super- alloy remained brittle at elevated temperatures. ${ }^{19)}$ Fractographic observations revealed that cracks are preferentially initiated at the MC carbide/matrix interface in Mar-M247 superalloys at elevated temperature. ${ }^{20)}$ The same conclusion was reached by Kaufman, ${ }^{21)}$ who proved that script-like MC carbides are extremely brittle and may act as crack initiation sites or crack propagation paths. Baldan ${ }^{22)}$ also noted that the size of the carbide particles dominates the creep rupture ductility, and that fine dispersion increases creep ductility.

Bhambri et al. ${ }^{23)}$ proposed that MC carbide is faceted and octahedral with $\{111\}$ faces and rapid growth in the $\langle 100\rangle$ direction during solidification. Accordingly, elongated or script-like morphology of MC carbide is formed. As mentioned previously, $\mathrm{Zr}$ addition has a strong tendency to disslove in carbide, possibly affecting the transport of carbon and carbide-forming elements, such as Ta, Hf, or Ti. Therefore, the addition of $\mathrm{Zr}$ to superalloy possibly results in the isotropic growth of carbides during solidification, and eventually leads to the refinement and spheroidization of MC carbide in fine-grain CM 247 LC superalloy. 


\subsection{Effect of $\mathrm{Zr}$ on mechanical properties}

Tensile test results can be explained by the Hall-Petch equation; $\sigma=\sigma_{0}+K d^{-1 / 2}$, where $\sigma$ is the yield stress; $\sigma_{0}$ is the "fraction stress," representing the overall resistance of the crystal lattice to dislocation movement; $K$ is the "locking parameter," which measures the relative contribution of the grain boundaries to hardening, and $d$ is the grain size. In this study, $d$ is constant, such that $\sigma_{0}$ and $K$ strongly affect the strength of fine-grain CM 247 LC alloy. Zr prefers to be in solid solution in matrix ( $\gamma, \gamma^{\prime}$ or carbide), so $\sigma_{0}$ increases as $\mathrm{Zr}$ is added. $\mathrm{Zr}$ additions also appear to annihilate grainboundary vacancies, result in increasing the value of $K$ thus increasing the structural perfection and increasing bond strength between the GBs. Hence, the tensile strength increases with the amount of minor $\mathrm{Zr}$ addition at $300 \mathrm{~K}$. The strength of the grain boundary determines the hightemperature strength of polycrystalline alloys, because the grain boundary is weaker than the inside of the grains at elevated temperature. The results concerning the fine-grain CM 247 LC superalloys show that minor $\mathrm{Zr}$ addition may alter the carbide morphology which promotes the retardation of the dislocation gliding and crack propagation. Therefore the yield strength and elongation of fine-grain CM 247 LC alloy increase with the $\mathrm{Zr}$ content at $1033 \mathrm{~K}$.

Based on the creep tests results, the initiation and propagation of cracks during creep are clearly retarded in fine-grain CM 247 LC with 0.15 mass\% Zr, substantially prolonging the rupture life. According to the creep deformation map of a CM 247 LC-related superalloy, ${ }^{24)}$ the creep mechanism at $1033 \mathrm{~K} / 725 \mathrm{MPa}$ involves the gliding of dislocations and the creep mechanism at $1200 \mathrm{~K} / 345 \mathrm{MPa}$ involves the sliding of grain boundaries and the climbing of dislocations. Thus, creep behavior is dominated by the interaction between dislocations and obstacles such as grain boundaries, precipitates or carbides. Figure 3 indicates that fine-grain CM 247 LC castings with more than 0.04 mass\% $\mathrm{Zr}$ exhibit sparse script-like carbides with a tendency to have a blocky or discrete carbide morphology, which promotes the retardation of the dislocation gliding and the grain boundary sliding, and to form barriers to the crack propagation. Additionally, $\mathrm{Zr}$ was detected to enrich at the grain boundary, which leads to spread the deformations that reduce stress concentrations at grain boundaries, substantially retarding crack initiation and propagation, and increasing the rupture life and elongation. Moreover, a mixed crack propagation mode is observed (Figs. 8(a)-(d)) in fine-grain CM 247 LC at $1033 \mathrm{~K} / 725 \mathrm{MPa}$ and $1200 \mathrm{~K} / 345 \mathrm{MPa}$. The crack propagation mode associated with a fine-grain structure is determined to be principally intergranular and transgranular, cracking along the grain boundary is less in CZ4 (0.15 mass\% Zr) specimens.
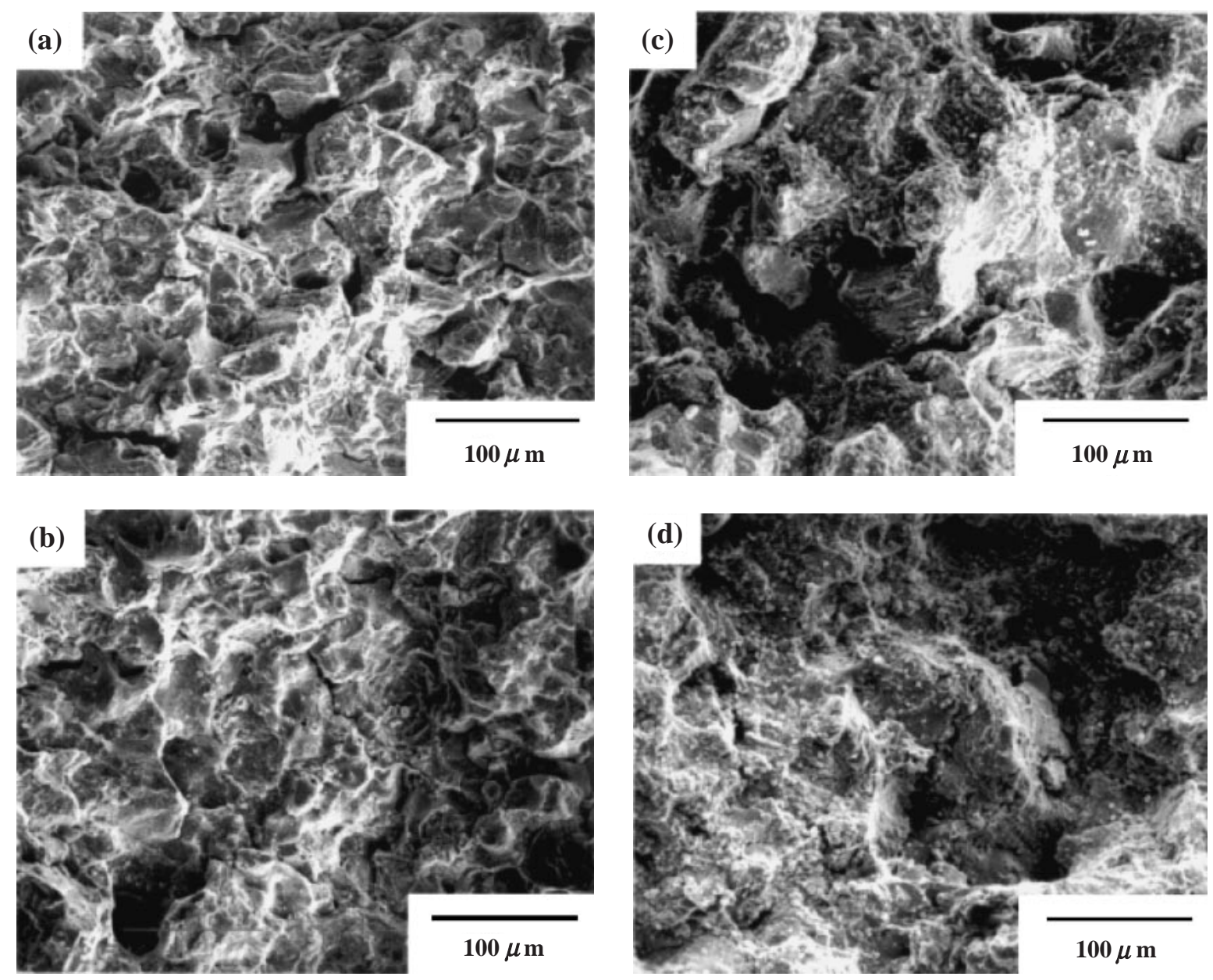

Fig. 8 Fractrography of fine-grain CM $247 \mathrm{LC}$ superalloy with (a) 0.015 mass $\% \mathrm{Zr}$, and (b) 0.15 mass $\% \mathrm{Zr}$ tested at $1033 \mathrm{~K} / 725 \mathrm{MPa}$ and fine-grain CM 247 LC superalloy with (c) 0.015 mass $\% \mathrm{Zr}$, and (d) 0.15 mass \% Zr tested at $1200 \mathrm{~K} / 345 \mathrm{MPa}$. 


\section{Conclusion}

(1) Minor $\mathrm{Zr}$ additions inhibit the formation of script-like $\mathrm{MC}$ carbides and cause the refinement and spheroidization of MC carbides, while not affecting the sizes of grains.

(2) Minor $\mathrm{Zr}$ additions promote the yield strength at $300 \mathrm{~K}$ as well as both the yield strength and elongation at $1033 \mathrm{~K}$, reducing the possibility of bursting of the hub in small gas turbine engines.

(3) Minor $\mathrm{Zr}$ additions effectively increase creep life and rupture elongation. In particular, the creep life of finegrain CM 247 LC superalloy with 0.15 mass\% $\mathrm{Zr}$ is double that of the alloy with 0.015 mass $\% \mathrm{Zr}$ at either $1033 \mathrm{~K} / 725 \mathrm{MPa}$ or $1200 \mathrm{~K} / 345 \mathrm{MPa}$.

(4) AES observations reveal that $\mathrm{Zr}$ may enrich at grain boundaries and boride/matrix interfaces, and become solid solution in the carbide and matrix, possibly changing the primary MC carbide morphology and inhibiting the formation of script-like carbide. These tendencies promote the accommodation of stress and retard the initiation and propagation of cracks, increasing the tensile strength and creep resistance of the alloy.

(5) The experimental results demonstrate that optimal $\mathrm{Zr}$ additions promote the performance of fine-grain $\mathrm{CM}$ 247 LC superalloys in small gas turbine engines, by increasing yield strength at operating temperature of the hub, protecting the parts from bursting, and increasing creep strength under operating condition of the blade.

\section{Acknowledgements}

The authors would like to appreciate the National Science Council of the Republic of China for financially supporting this research under Contract No. NSC 91-2623-7-002-008.

\section{REFERENCES}

1) F. Liu, W. Yuan, X. Tang, A. Yang and W. Chen: Materials Engineering, (1995) 7-11.

2) C. T. Sims, N. S. Stoloff and W. C. Hagel: Superalloy II, (John Wiley \& Sons, New York, 1987) pp. 425-426.

3) G. K. Bouse and M. R. Behrendt: Superalloy 718, E. A. Loria, ed., (TMS, Warrendale, PA, 1989) pp. 319-328.

4) K. Harris and R. E. Schwer: TMS-AIME Fall Meeting, St. Louis, MO, 1978.

5) K. Harris and R. E. Schwer: AVS 6th Int. Vac. Met. Conf., (San Diego, CA, 1979) pp. 7-8.

6) K. Harris, G. L. Erickson and R. E. Schwer: 5th Int. Symposium on Superalloys, (Champion, PA, 1984) pp. 221-230.

7) K. Harris, G. L. Erickson and R. E. Schwer: 1982 AIME Annual Meeting, (Dallas, Texas, Feb. 1982) pp. 1-31.

8) C. T. Sims, N. S. Stoloff and W. C. Hagel: Superalloy II, (John Wiley \& Sons, New York, 1987) pp. 170-171.

9) J. K. Tien and R. P. Gamble: Metall Trans. 2 (1971) 1663-1667.

10) C. T. Sims, N. S. Stoloff and W. C. Hagel: Superalloy II, (John Wiley \& Sons, New York, 1987) pp. 120-121.

11) C. S. Lee, G. W. Han, R. E. Smallman, D. Feng and J. K. Lai: Acta Metall. 47 (1999) 1823-1830.

12) Metals Handbook Vol. 8, 8th ed, American Society for Metals, (Metals Park, OH, 1973) p. 262.

13) S. Ochiai, Y. Oya and T. Suzuki: Acta Metall. 32 (1984) 289-298.

14) C. T. Liu and C. L. White: Materials Research Society Symposium Proceeding 39 (1985) pp. 365-380.

15) S. E. Hsu, N. N. Hsu, C. H. Tong, C. Y. Ma and S. Y. Lee: Proc. Annu. Conf. Of Chinese Society of Materials Science, (1986) pp. 423-429.

16) J. E. Doherty, B. H. Kear and A. F. Giamei: J. Met. 23 (1971) 59-62.

17) D. N. Duhi and C. P. Sullivan: J. Met. 23 (1971) 38-40.

18) P. S. Kotval, J. D. Venables and R. W. Calder: Metall. Trans. 3 (1972) 453-458.

19) H. Y. Bor, C. G. Chao and C. Y. Ma: Scr. Mater. 38 (1998) 329-335

20) H. Y. Bor, C. G. Chao and C. Y. Ma: Metall and Mater. Trans. A 30 (1999) 551-561.

21) M. Kaufman: Proc. Superalloys 1984, M. Gell, ed., (AIME, Warrendale, PA, 1984) pp. 43-52.

22) A. Baldan: Z. Metallkd. 83 (1992) 750-757.

23) A. K. Bhambri and T. Z. Kattamis: Metall. Trans. B 6 (1975) 523-537.

24) C. T. Sims, N. S. Stoloff and W. C. Hagel: Superalloy II, (John Wiley \& Sons, New York, 1987) pp. 39-40. 